\title{
Comparative studies between ant lion optimizer and evolutionary programming in optimal distributed generation placement
}

\author{
Nur Atiqah Abdul Rahman ${ }^{1 *}$, Zulkiffli Abdul Hamid², Ismail Musirin², Nur Ashida Salim ${ }^{2}$ and \\ Muhd Firdaus Muhd Yusoff ${ }^{1}$ \\ Faculty of Electrical Engineering, Universiti Teknologi MARA, Cawangan Sarawak, Malaysia ${ }^{1}$ \\ Faculty of Electrical Engineering, Universiti Teknologi MARA, 40450, Shah Alam, Selangor, Malaysia ${ }^{2}$
}

Received: 7-October-2020; Revised: 15-February-2021; Accepted: 19-February-2021

(C)2021 Nur Atiqah Abdul Rahman et al. This is an open access article distributed under the Creative Commons Attribution (CC BY) License, which permits unrestricted use, distribution, and reproduction in any medium, provided the original work is properly cited.

\begin{abstract}
Integration of Distributed Generation (DG) has become one of the popular research interests in power system. DG used small-scale technologies to generate electricity near to the consumer and the size is normally small, range from $50 \mathrm{MW}$ to $100 \mathrm{MW}$. However, in order to integrate DG into the power system distribution, it is very crucial to consider several factors such as location, size and the number of DG to maintain its benefits. This paper proposes comparison of three techniques for optimal placement of $D G$ in distribution system. The optimal placement was done using Evolutionary Programming (EP), Ant Lion Optimizer (ALO) and Loss Sensitivity Factor (LSF) to minimize the power losses in distribution system. These techniques were tested in three conditions; base case (without loading increment), $50 \%$ loading and $100 \%$ loading to observe the performance of the techniques in various phenomena. The test was conducted using IEEE 10-bus radial distribution system and the result shows that the integration of DG does minimize the power losses with $\mathrm{ALO}$ provides the most promising results.
\end{abstract}

\section{Keywords}

Optimal placement distributed generation, Evolutionary programming, Ant lion optimizer, Loss sensitivity factor.

\section{Introduction}

Integration of DG in power system has become one of the main interests for researchers. This is because DG can provide a lot of advantages to the system such as improving the voltage profile, minimizing real power loss, enhancing the reliability as well as power quality [1] and at the same time a long distance transmission of electricity can be avert [2].

There were many definitions of DG that can be found in literature [3-6], but according to International Energy Agency (IEA), DG can be defined as an electrical source that is directly connected to the distribution network in order to supply and sustain the distribution network to a local customer [7]. There are few numbers of DG technologies that are commonly used such as diesel generators, microturbines, solar DG (PV), wind power, hydroelectricity and fuel cells. The most prominent DG technology is diesel generator because it is convenient in standalone operation.

*Author for correspondence
On the other hand, microturbines are not environmentally sustainable since they produce toxic emissions. However, this drawback can be eliminated by using PV and wind turbine DG as they produce clean emission [8]. All these DG technologies can be classified into four types as follow [9]:

Type1: Inject only active power $(\mathrm{P})$ - Fuel cell, PV and wind turbine.

Type2: Inject active (P) and reactive power (Q)Synchronous machine in gas turbine.

Type3: Absorb only reactive power (Q)Synchronous Compensator

Type 4: Inject active power $(\mathrm{P})$ and consume reactive power $(\mathrm{Q})$ - Induction generator used in wind farms.

Since DG integration can provide a lot of advantages for power system, a good planning should be imposed in order to avoid severe impact to the overall system. Vigorous integration of DG may affect the grid stability and power system quality [10]. Apart from that, improper planning may also lead to voltage flicker, over voltages, excessive power losses, 
increase short circuit current [8] and a risk of reclosing out of phase, which will damage the adjacent loads and feeders of the distribution system [11].

Thus, the main objective of this research is to optimal allocate the DG in distribution system using three approaches, EP, ALO and LSF to minimize the power loss of a radial distribution system which given by following equation [12]:

$f(x)=\min \left(\sum_{i=1}^{n b u s} P_{\text {loss }}\right)$

Which subject to following constraint:

$0.95 p u<V_{\text {min }}<1.05 p u$

$P_{D G \min }<P_{D G}<P_{D G \max }$

$0<P_{f_{-D G}}<1$

\section{Literature review}

A proper planning in terms of sizing and placement of DG in distribution system is a crucial process to avoid severe impacts and to ensure the performance of distribution network. There are many techniques were proposed in literature for optimal placement and sizing of DG.

These techniques can be categorized into 4 groups which are the classic approaches, sensitivity analysisbased approaches, metaheuristic-based approaches and hybrid approaches [8]. Classic approaches such as mixed-integer linear programming and mixedinteger non-linear programming was proposed in [13-16] to minimize the cost, power losses and improve voltage stability. These approaches are easy to implement and computationally efficient. However, it requires certain decision variable and also can lead to inaccurate solutions [17]. On the other hand, sensitivity analysis is a technique which used to find a proper location of DG based on sensitivity index. This approach will find the most sensitive location to place the DG. It also requires small computation time but the extent of the solution's optimality is unknown [8].

Due to these limitations, the metaheuristic-based approach has become the popular technique used by researchers to find the optimal location and sizing of the DG. Techniques such as Genetic Algorithm (GA), Particle Swarm Optimization (PSO), Tabu Search (TS), Ant Colony Optimization (ACO), Cuckoo Search (CS), Evolutionary Programming (EP) and Ant Lion Optimizer (ALO) can be categorized as metaheuristic-based approaches.

The interest of metaheuristic approaches is because it does not require precondition in objective function and very efficient in solving optimization problems [18-22]. Despite these benefits, it has the possibilities to trap in local optima instead a global one [8]. This paper presents the comparative study which intends to perform an analysis of the performance comparison in terms of power loss minimization between three different methods; loss sensitivity technique (analytical), EP and ALO (metaheuristic) under various situations. The rest of this paper is organized as follow; in Section 2, all techniques used are discussed. While in section 3, result from simulation using all these techniques in various situations are presented and analyzed. Eventually, the conclusion is presented in Section 4.

\section{Methodology}

In this section, the three techniques used for optimal placement of DG in distribution system are discussed as follows. The objective of this research is to minimize the power loss of a radial distribution system using EP, ALO and LSF.

All the techniques will be tested under three different cases: base case, $50 \%$ loading and $100 \%$ loading. Type 1 DG is chosen since it is one of the fastestdeveloped technologies providing the most assured energy sources [23]. The algorithm was run by using MATLAB R2020a software with $1.6 \mathrm{GHz}$ Dual-Core Intel Core i5 processor.

\subsection{Loss sensitivity factor (LSF)}

The LSF is a technique based on loss change with respect to generation increment [24]. This technique determines the best bus candidate for DG allocation. The search area and time consumption can be reduced through this approach where the highest index will indicate the best location for DG installation.

This technique can be represented by the following equations in terms of real and reactive power respectively [12]:

$L S_{k}=\frac{P_{\text {loss }}^{a}-P_{\text {loss }}^{b}}{\Delta P_{k}}$
$L S_{k}=\frac{Q_{\text {loss }}^{a}-Q_{\text {loss }}^{b}}{\Delta Q_{k}}$

Where:

$L S_{k} \quad: \quad$ Loss sensitivity at $k$-th bus

$P_{\text {loss }}^{b}, Q_{\text {loss }}^{b} \quad: \quad$ Real and reactive power losses

before generation incremen

$P_{\text {loss }}^{a}, Q_{\text {loss }}^{a} \quad: \quad$ Real and reactive power losses after generation increment

$\Delta P_{k}, \Delta Q_{k} \quad: \quad$ Generation increment or DG's injected power 
Pre load flow simulation was run to obtain the value of losses before DG integration. After installation of DG at $k$-th bus, post load flow was run to obtain the value of losses after DG integration. This process will be repeated until all busses have been tested. The bus with the highest loss sensitivity index will be designated as a priority bus for DG integration.

\subsection{Evolutionary programming (EP)}

EP is one of the members of Evolutionary Algorithm (EA) under Artificial Intelligence (AI). This technique mimics the natural evolution and genetic algorithm [25]. It consists of four main parts which are, initialization, mutation, combination and selection. Figure 1 presents the flow chart for overall process of EP.

The population is first initialized randomly and the fitness for each solution is then calculated based on objective function, in this case, power loss

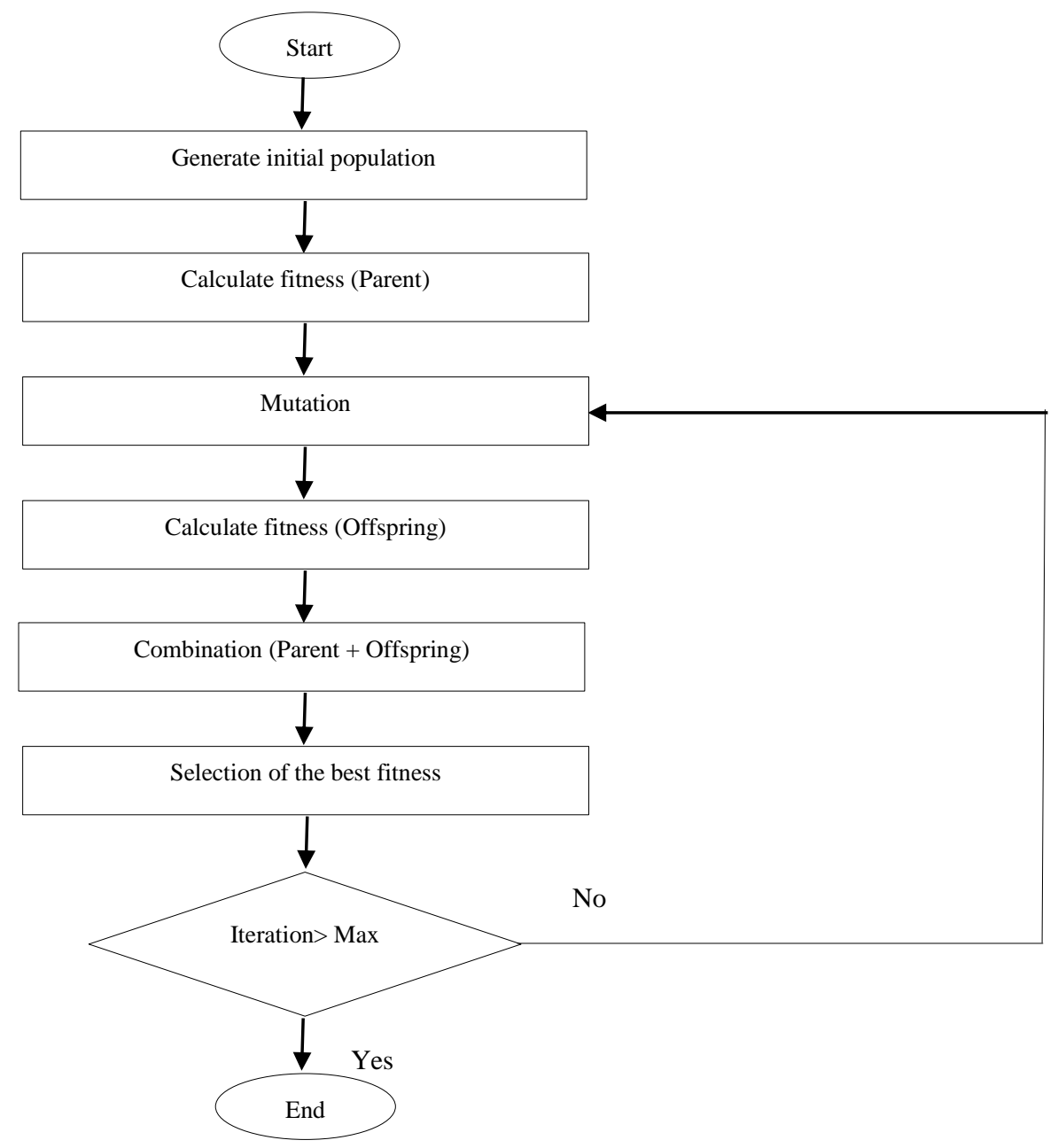

minimization. This fitness will act as parent before being evaluated to the next step.

In mutation process, Gaussian distribution is used to generate the random number to be added to the parent $\left(y_{i}\right)$ to obtain offspring $\left(y_{i}^{\prime}\right)$ by using the following equation [25] :

$y_{i}^{\prime}=y_{i}+N\left(0, \sigma_{i}^{2}\right)$, for $i=1,2 \ldots \ldots n$

where $N\left(0, \sigma_{i}^{2}\right)$ represents a Gaussian random variable with mean 0 and standard deviation $\sigma i$.

Next, the parent and offspring are combined. The selection is then conducted to obtain the best candidates from parent and offspring based on the fitness quality. This process will be repeated until the termination condition is reached.

Figure 1 Evolutionary Programming algorithm 


\subsection{Ant lion optimizer (ALO)}

ALO is a nature-inspired algorithm that was developed by Mirjalili in 2015 [26] which mimics the hunting behaviour of antlions in nature. Originally, the word antlion was taken from the unusual hunting activity of their prey, ants. Through its extensive jaw to trap their prey, antlions can dig sand into cone shaped as a trap. This cone shape was achieved by tossing out sand in a spherical shape. Until the trap is ready, while waiting for their prey, they will hide at the bottom of this cone-shape trap. This cone has been made sharp enough that it is easy for the prey to slip to the bottom of the pit.
Not all prey would fall instantly to the bottom of the pit, as this prey is going to try to escape. Antlions can throw sand at the edge of the trap to ensure that this prey can be trapped, making the prey slip down to the bottom of the trap. If the prey is captured, the prey will be dragged under the soil and devoured by antlions. The leftover is thrown out of the pit, and the antlions are ready for the next search by modifying the pit. The overall algorithm for ALO is presented in Figure 2.

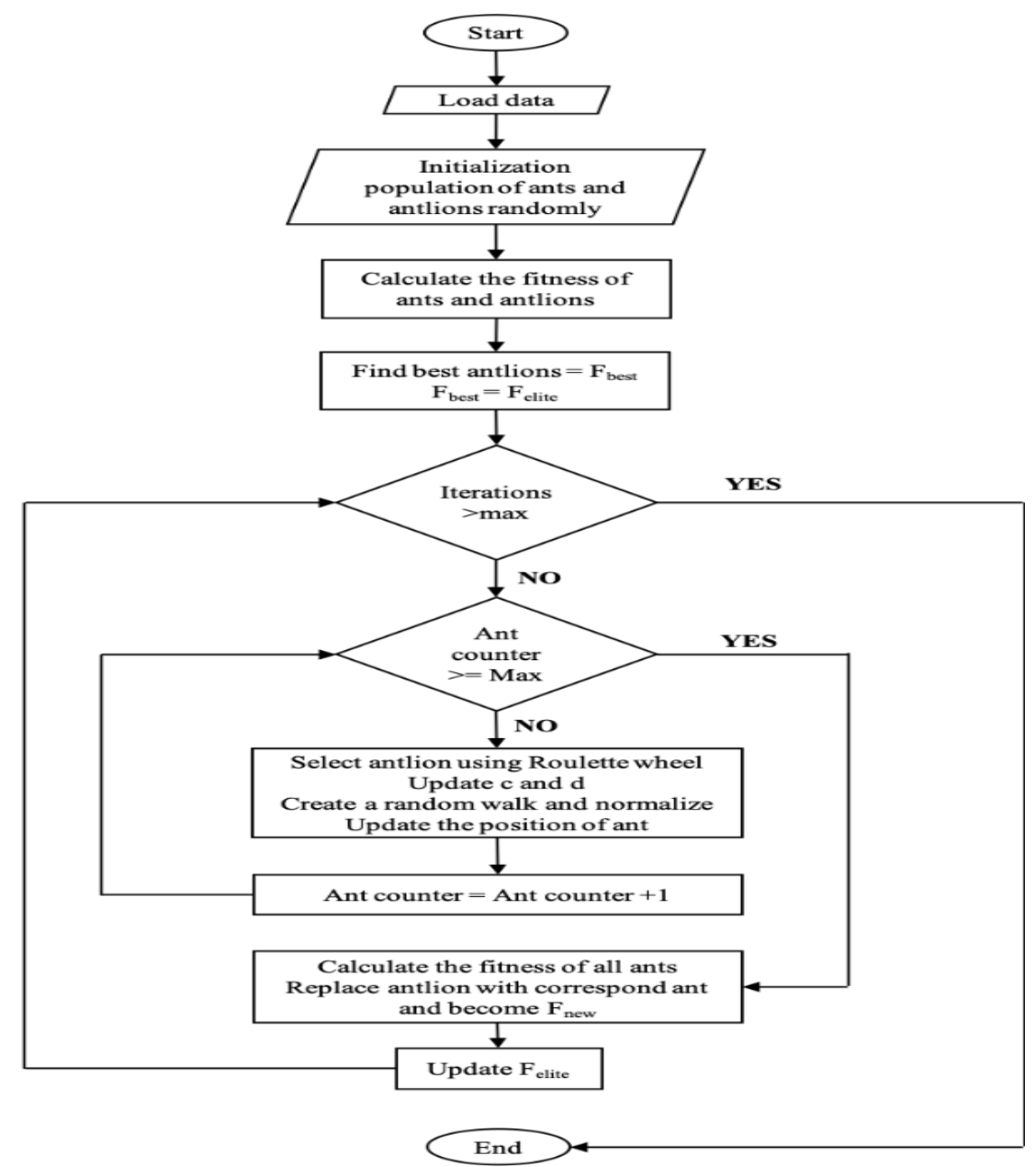

Figure 2 Ant lion optimizer algorithm

The optimal placement of DG starts by loading the data that is going to be used. After the data was loaded, the initialization will be done randomly to generate the population of ant and antlions based on the following equations:

$$
\begin{array}{r}
X(t)-\left[0, \operatorname{cumsum}\left(2 r\left(t_{1}\right)-1, \operatorname{cumsum}\left(2 r\left(t_{2}\right)\right.\right.\right. \\
-1, \ldots, \text { cumsum }\left(2 r\left(t_{n}\right)-1\right]
\end{array}
$$

$$
r(t)= \begin{cases}1 & \text { if rand }>0.5 \\ 0 & \text { if rand } \leq 0.5\end{cases}
$$


Next, the fitness for each ant and antlion will be calculated based on desired objective function. The fitness then will be ranked, and the uppermost fitness will be the best fitness and is set as $F_{\text {best }}$. The antlions correspond to this $F_{\text {best }}$ will be treated as elite.

Afterwards, the iteration will start until the termination criterion is reached. For each ant, the antlions will be selected using Roulette-Wheel selection, followed by the update process of $c$ and $d$ parameters using the following equations:

$$
\begin{aligned}
& c^{t}=\frac{c^{t}}{I} \\
& d^{t}=\frac{d^{t}}{I} \\
& \text { Antlion }_{j}^{t}=\text { Ant }_{i}^{t} \text { if } f\left(\text { Ant }_{i}^{t}\right)>f\left(\text { Antlion }_{j}^{t}\right)
\end{aligned}
$$

Then, the random walk will be created using equation $(2,3,1)$ and normalized via the following equation:

$X_{i}^{t}=\frac{\left(X_{i}^{t}-a_{i}\right) \times\left(d_{i}-c_{i}^{t}\right)}{\left(d_{i}^{t}-a_{i}\right)}+c_{i}$

Next, the position of ant will be updated and this process will be repeated until the maximum number of ants is reached. The fitness for all ants will be calculated and comparison is done such that every antlion will replace the corresponding ant if it is fitter (in terms of fitness quality). Again, this fitter antlion then will be updated to replace the previous elite antlion if it is fitter. The overall process will be repeated until the maximum iteration is reached.

\section{Result and discussions}

In this section, the result obtained for loss minimization is presented. There are two techniques that have been utilized to observe the performance on power loss and voltage profile which are the EP and ALO. These two algorithms have been utilized to minimize the power losses for IEEE 10-bus radial distribution system. Comparison with LSF is presented to observe the performance of the metaheuristic algorithms. There are four situations which are:
1. Case 1
: Base case (no load increment)
2. Case 2 : $50 \%$ of maximum loading
3. Case 3

\section{Overall performance}

\subsection{Case 1: Base case}

Single type 1 DG was chosen in this study and pre load flow was run to obtain the power loss without DG integration, which is 0.04840 MW. Table 1 tabulates the power loss for IEEE 10-bus radial distribution system after the implementation of EP and ALO.

From the table, it clearly shows that after DG installation, the power losses have decreased significantly for all buses and for both algorithms.

The result also shows that when DG was installed at bus 8 using EP, the power loss reduces to 0.01593 MW, which is $67.08 \%$ decrease. The lowest improvement on power loss is at bus 2 with only $18.91 \%$ decrease. This shows that by installing DG at bus 8 with EP implementation, the power loss can be minimized significantly compared to other buses.

The implementation of ALO also shows power loss minimization at all busses. The losses decrease significantly with the integration of DG into the system. As in EP, bus 8 shows the highest improvement in terms of power loss with $69.32 \%$ decrease (post-loss of $0.01485 \mathrm{MW}$ ). Bus 2 still records the lowest improvement of $19.33 \%$ decrease.

Hence, it is clear that bus 8 is the optimal location for DG placement according to both methods, i.e. EP and ALO. In addition, this result also justifies that the placement of DG in 10-bus radial distribution system promises an improvement on the real power loss.

On the other hand, Figure 3 presents the graphical comparison of power loss as produced by EP and ALO. From the figure, it shows that the power loss decreases as the order of the bus number increases, and this is true for both methods. However, the ALO gives better result of power loss compared to EP for all buses. This finding justifies the benefit of using ALO over EP in DG placement problem. Table 2 summarizes the power loss minimization obtained from EP and ALO. 
Table 1 Real power loss $\left(\mathrm{P}_{\text {loss }}\right)$ and percentage of losses reduction $\left(\Delta \mathrm{P}_{\text {loss }}\right)$ for individual placement of DG - IEEE 10-bus system, base case

\begin{tabular}{|c|c|c|c|c|}
\hline & \multicolumn{2}{|c|}{$P_{\text {loss }}(\mathrm{MW})$} & \multicolumn{2}{|c|}{$\Delta P_{\text {loss }}(\%)$} \\
\hline & EP & ALO & EP & ALO \\
\hline Without DG & 0.04840 & 0.04840 & - & - \\
\hline 2 & 0.03925 & 0.03905 & 18.91 & 19.33 \\
\hline 3 & 0.03228 & 0.03149 & 33.30 & 34.94 \\
\hline 4 & 0.02596 & 0.02490 & 46.36 & 48.56 \\
\hline 5 & 0.02134 & 0.02012 & 55.92 & 58.43 \\
\hline 6 & 0.01824 & 0.01698 & 62.32 & 64.92 \\
\hline 7 & 0.01671 & 0.01551 & 65.48 & 67.96 \\
\hline 8 & 0.01593 & 0.01485 & 67.08 & 69.32 \\
\hline 9 & 0.01628 & 0.01539 & 66.37 & 68.20 \\
\hline 10 & 0.01758 & 0.01695 & 63.68 & 64.99 \\
\hline
\end{tabular}

Table 2 Power loss comparison with implementation of EP and ALO -base case

\begin{tabular}{cccc}
\hline Algorithms & DG Location (Bus) & $\boldsymbol{P}_{\text {loss }}(\mathbf{M W})$ & Improvement $(\%)$ \\
\hline EP & 8 & 0.01593 & 67.08 \\
\hline ALO & 8 & 0.01485 & 69.32 \\
\hline
\end{tabular}

Ploss for IEEE 10-Bus System Using EP and ALO (Base Case)

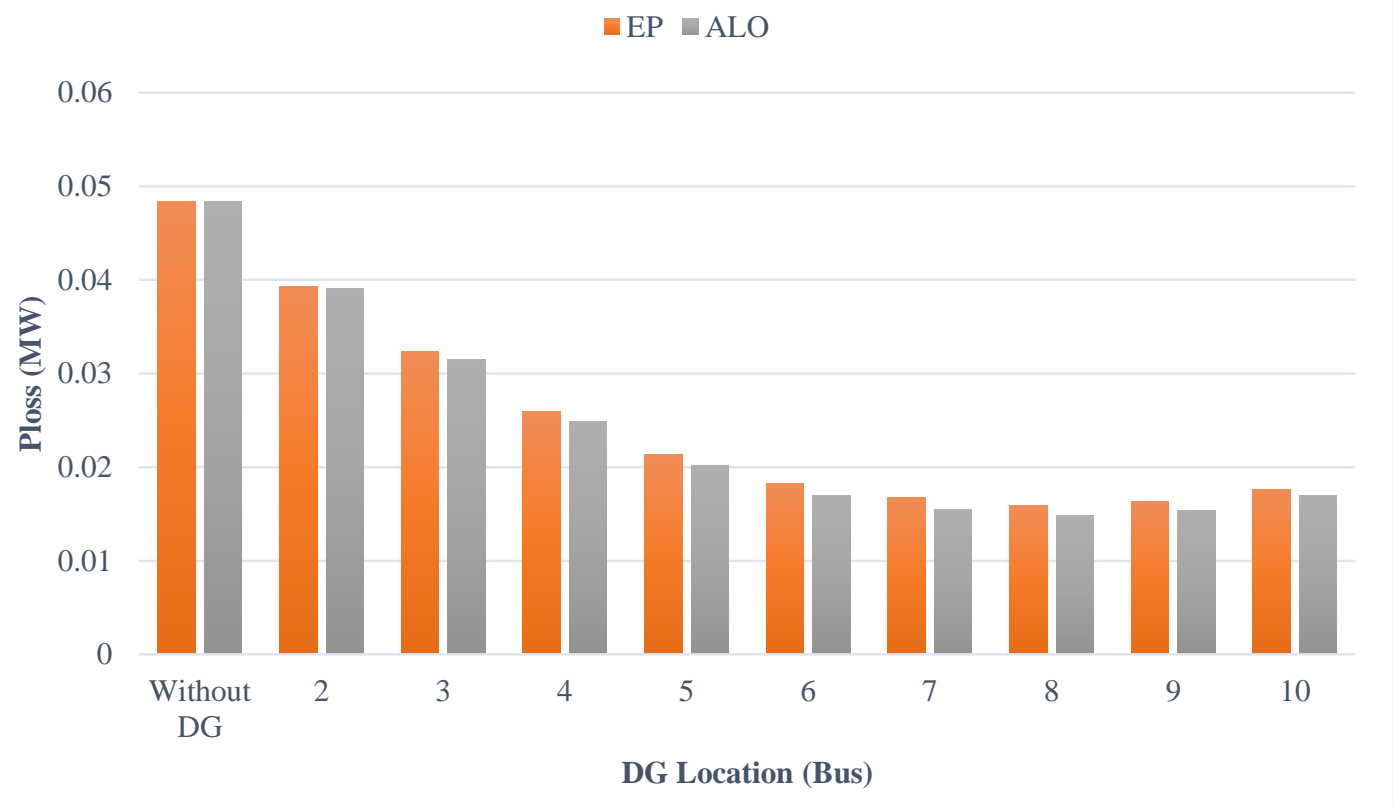

Figure 3 Improvement in power loss using EP and ALO - base case

\subsection{Case 2: $50 \%$ of maximum loading}

In order to observe the performance of EP and ALO in various condition, second test was conducted by increasing the loading to $50 \%$. The same type-1 DG were installed to observe the overall performance. Table 3 demonstrates the result of power loss after EP and ALO implementation. The pre-load flow was run to obtain the value of power loss without DG integration, which is $0.06088 \mathrm{MW}$ By increasing the load, the power loss has slightly increased. After the DG integration, however, the loss has been reduced significantly either using EP or ALO. The result from Table 2 justifies that by installing DG at any busses, 
there will be a reduction on the magnitude of the power loss.

The result also shows that bus 8 is the best location for DG placement using EP and ALO, where both methods yield to $54.08 \%$ and $55.83 \%$ power loss decrease respectively. Once again, the ALO has outperformed EP by providing a better result.

Figure 4 presents the graphical comparison of power loss resulted from EP and ALO implementation.
From this chart, it shows that the power loss decreases as the order of the bus number increases based on both methods. It is obvious that the ALO gives better result of power loss compared to EP. This finding justifies the benefit of using ALO over EP even the loading is at $50 \%$ of the maximum. Table 4 summarizes the power loss minimization obtained from EP and ALO at 50\% loading.

Table 3 Real power loss (Ploss) and percentage of losses reduction ( $\triangle$ Ploss) for individual placement of DG - IEEE 10-bus system, $50 \%$ loading

\begin{tabular}{|c|c|c|c|c|}
\hline & \multicolumn{2}{|c|}{$P_{\text {loss }}(\mathrm{MW})$} & \multicolumn{2}{|c|}{$\Delta P_{\text {loss }}(\%)$} \\
\hline & EP & ALO & EP & ALO \\
\hline Without DG & 0.06088 & 0.06088 & - & - \\
\hline 2 & 0.05386 & 0.05148 & 11.53 & 15.44 \\
\hline 3 & 0.04466 & 0.04386 & 26.65 & 27.97 \\
\hline 4 & 0.03824 & 0.03717 & 37.18 & 38.95 \\
\hline 5 & 0.03353 & 0.03230 & 44.92 & 46.94 \\
\hline 6 & 0.03036 & 0.02909 & 50.13 & 52.23 \\
\hline 7 & 0.02879 & 0.02757 & 52.72 & 54.71 \\
\hline 8 & 0.02799 & 0.02689 & 54.03 & $\mathbf{5 5 . 8 3}$ \\
\hline 9 & 0.02834 & 0.02745 & 53.45 & 54.91 \\
\hline 10 & 0.02969 & 0.02907 & 51.23 & 52.26 \\
\hline
\end{tabular}

Table 4 Power loss comparison with implementation of EP and ALO - 50\% loading

\begin{tabular}{cccc}
\hline Algorithms & DG Location (Bus) & $\mathbf{P}_{\text {loss }}$ (MW) & Improvement (\%) \\
\hline EP & 8 & 0.02799 & 54.03 \\
\hline ALO & 8 & 0.02689 & 55.83 \\
\hline
\end{tabular}

Ploss for IEEE 10-Bus System Using EP and ALO (50\% Loading)

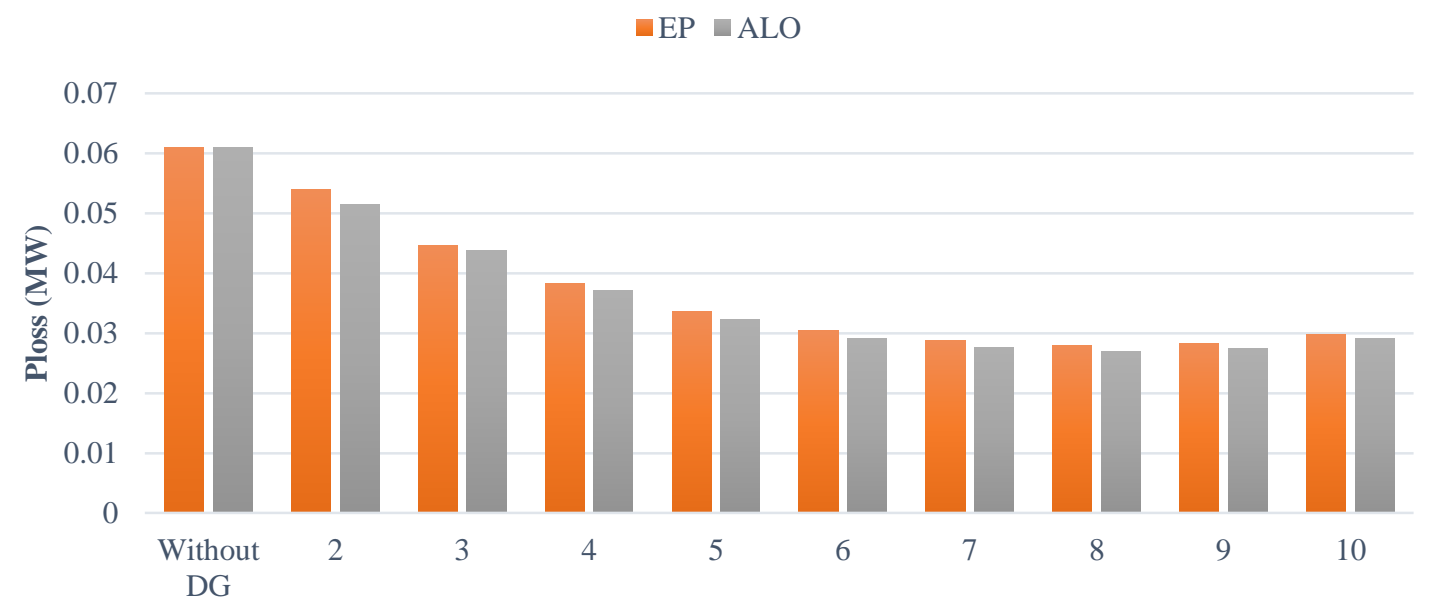

DG Location (Bus)

Figure 4 Improvement in power loss using EP and ALO-Case 2 


\subsection{Case 3:100\% loading}

For case 3, the loading has been increased to $100 \%$ and the power loss is observed for both EP and ALO algorithm. Result for case 3 was tabulated in Table 5 .

The power loss before DG integration was found to be $0.08708 \mathrm{MW}$. As in Case 1 and 2, the results for post-optimization yield to the same trend of losses minimization, with bus 8 being the best location for DG placement. The bus results in $38.49 \%$ and $39.76 \%$ of power loss decrease using EP and ALO respectively. Still, the ALO outperforms EP a little bit as its losses reduction is better. As can be seen in Figure 5, the power loss reduces as the order of the bus number increases, for both methods.

Table 6 summarizes the whole result on power loss minimization as produced by EP and ALO. The result from Case 3 is sufficient to highlight the merit of ALO for optimal DG placement in distribution system.

Table 5 Real power loss (Ploss) and percentage of losses reduction ( $\triangle$ Ploss) for individual placement of DG - IEEE 10-bus system, $100 \%$ loading

\begin{tabular}{lllll}
\hline & $\boldsymbol{P}_{\text {loss }}(\mathbf{M W})$ & & $\boldsymbol{\Delta P}$ & $\mathbf{P}$ loss \\
\hline & $\mathbf{E P}$ & $\mathbf{A L O}$ & $\mathbf{E P}$ & $\mathbf{A L O}$ \\
\hline Without DG & 0.08708 & 0.08708 & - & - \\
\hline 2 & 0.08001 & 0.07760 & 8.12 & 10.89 \\
\hline 3 & 0.07068 & 0.06987 & 18.84 & 19.77 \\
\hline 4 & 0.06415 & 0.06306 & 26.34 & 27.59 \\
\hline 5 & 0.05932 & 0.05806 & 31.88 & 33.32 \\
\hline 6 & 0.05605 & 0.05475 & 35.64 & 37.13 \\
\hline 7 & 0.05441 & 0.05317 & 37.52 & 38.94 \\
\hline $\mathbf{8}$ & $\mathbf{0 . 0 5 3 5 7}$ & $\mathbf{0 . 0 5 2 4 6}$ & $\mathbf{3 8 . 4 9}$ & $\mathbf{3 9 . 7 6}$ \\
\hline 9 & 0.05393 & 0.05303 & 38.07 & 39.11 \\
\hline 10 & 0.05534 & 0.05472 & 36.45 & 37.16 \\
\hline
\end{tabular}

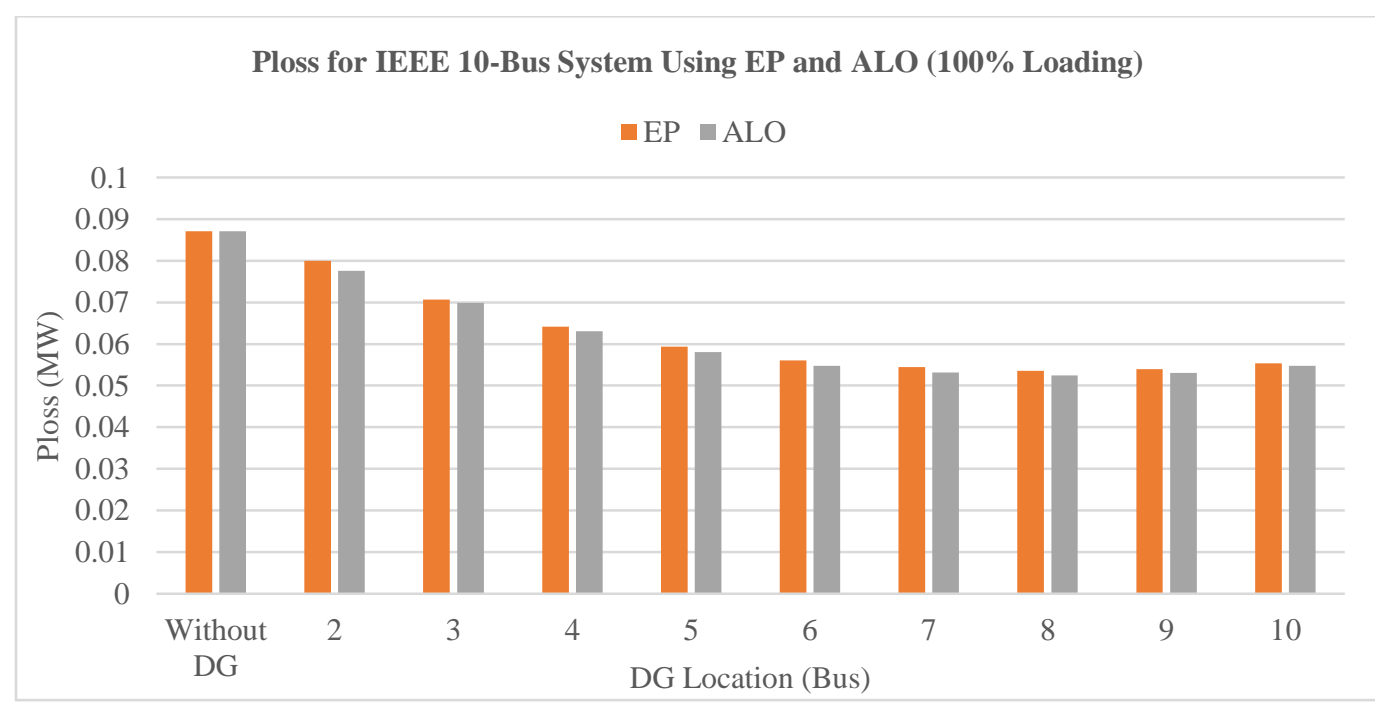

Figure 1 Improvement in power loss using EP and ALO - Case 3

Table 6 Power loss comparison with implementation of EP and ALO - 100\% loading

\begin{tabular}{cccc}
\hline Algorithms & DG Location (Bus) & $\mathbf{P}_{\text {loss }}$ (MW) & Improvement (\%) \\
\hline EP & 8 & 0.05357 & 38.49 \\
\hline ALO & 8 & 0.05246 & 39.76 \\
\hline
\end{tabular}

\subsection{0verall performance}

In order to observe the effectiveness of these two algorithms, the optimal DG placement was also implemented using the analytical technique: LSF. Based on the analysis, there are 4 buses with significant LS indices which are bus 2,3,4 and 1 in 
descending order. The result for power loss using LSF for these 4 buses is shown in Table 7.

It can be seen that, by using LSF, the best location is bus 4 for all 3 cases. However, the improvement given by LSF is not as good as EP and ALO. Figure 6 presents the overall comparison between the three techniques. From the figure, both EP and ALO outperform the LSF as they offered lower magnitude of power loss at post-optimization. This finding has justified the capability of optimization algorithms as a good choice of solving DG placement problem, with better accuracy and performance, within tolerable computation time.

Table 7 Power loss comparison using LSF for all cases

\begin{tabular}{llll}
\hline DG Location (Bus) & $\begin{array}{l}\mathbf{P}_{\text {loss }} \\
\text { (MW) } \\
\text { Case 1 }\end{array}$ & $\begin{array}{l}\mathbf{P}_{\text {loss }} \\
(\mathbf{M W}) \\
\text { Case 2 }\end{array}$ & $\begin{array}{l}\mathbf{P}_{\text {loss }} \\
\text { MW) } \\
\text { Case 3 }\end{array}$ \\
\hline 1 & 0.04840 & 0.06088 & 0.08708 \\
\hline 2 & 0.03928 & 0.05171 & 0.07784 \\
\hline $\mathbf{4}$ & 0.03189 & 0.04426 & 0.07028 \\
\hline
\end{tabular}

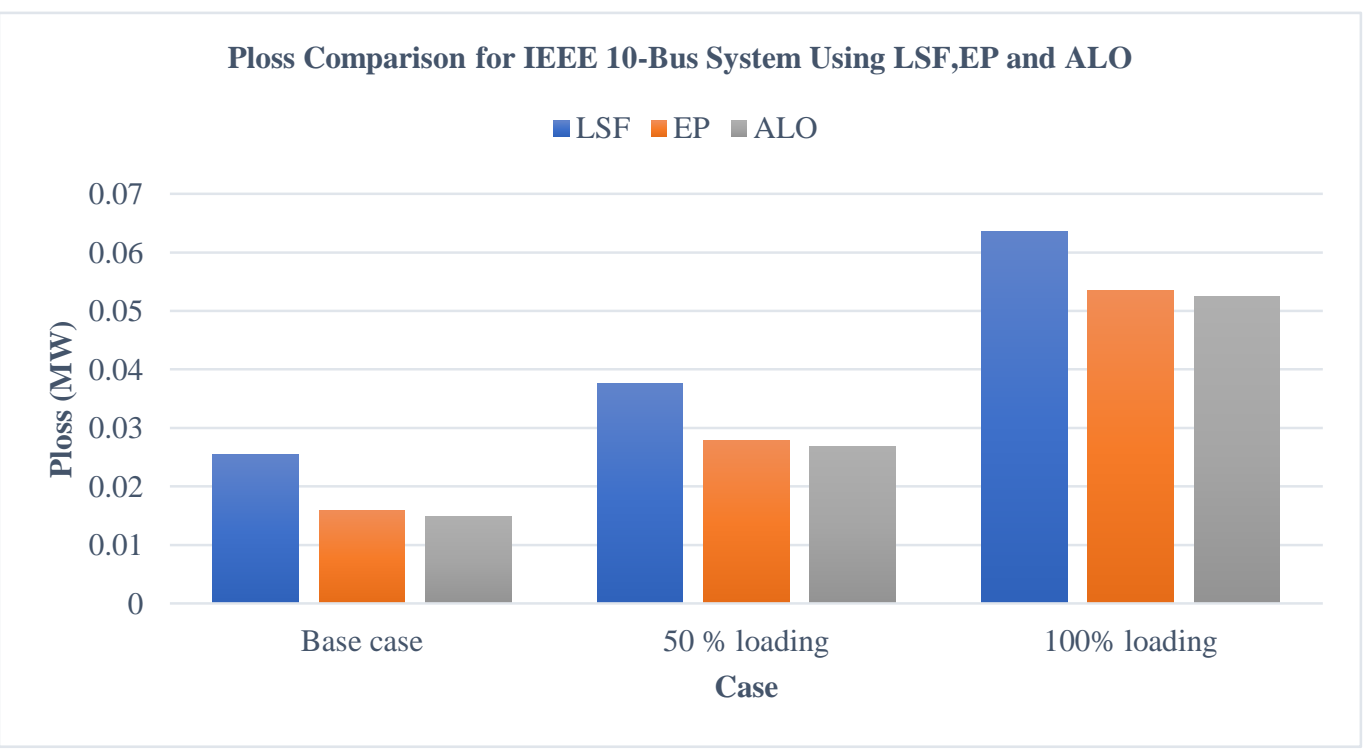

Figure 6 Improvement in power loss using EP, ALO and LSF for all cases

\section{Conclusion}

In conclusion, this paper has performed a thorough comparison between three different techniques for optimal placement of distributed generation using EP, ALO and LSF to minimize power losses in IEEE 10bus radial distribution system. The findings in this study reflect a promising output as the power loss can be reduced significantly via the optimal placement of DG. To highlight the merit among the three methods, the ALO has outperformed by resulting in the highest reduction of power loss in the system. The algorithm was tested using small system and can be computationally inefficient when work with large

system. Thus, for future works, this study can be 244 improved by combining the ALO with LSF to reduce the search space and computational time when working with large system.

\section{Acknowledgment}

The authors would like to acknowledge the Research Management Centre (RMC), Office of Deputy Vice Chancellor (DVC), Universiti Teknologi MARA (UiTM) Shah Alam, Selangor, Malaysia for the financial support of this research. This research is supported by RMC under the Research Entity Initiative (REI) Grant Scheme with project code: 600-IRMI/REI 5/3 (011/2018).

\section{Conflicts of interest}

The authors have no conflicts of interest to declare. 


\section{References}

[1] Gusnanda AF, Putranto LM. Effect of distributed photovoltaic generation installation on voltage profile: a case study of rural distribution system in yogyakarta Indonesia. In international conference on information and communications technology 2019 (pp. 750-5). IEEE.

[2] Zhong Z, Zhang Y, Shen H, Li X. Optimal planning of distributed photovoltaic generation for the traction power supply system of high-speed railway. Journal of Cleaner Production. 2020; 263:1-20.

[3] Ackermann T, Andersson G, Söder L. Distributed generation: a definition. Electric Power Systems Research. 2001; 57(3):195-204.

[4] Borges CL, Falcao DM. Optimal distributed generation allocation for reliability, losses, and voltage improvement. International Journal of Electrical Power \& Energy Systems. 2006; 28(6):413-20.

[5] Griffin T, Tomsovic K, Secrest D, Law A. Placement of dispersed generation systems for reduced losses. In proceedings of the annual Hawaii international conference on system sciences 2000 (pp. 9-pp). IEEE.

[6] Schweer A, Study committee power system planning and development international conference on large high voltage electric systems. Impact of Increasing Contribution of Dispersed Generation on the Power System. Cigré; 1999:46-55.

[7] Maribu KM. Distributed generation in liberalised electricity markets. A Summary of PhD Projects 2002. 2005.

[8] Jordehi AR. Allocation of distributed generation units in electric power systems: a review. Renewable and Sustainable Energy Reviews. 2016; 56:893-905.

[9] Jagtap KM. Impact of different types of distributed generation on radial distribution network. In international conference on reliability optimization and information technology 2014 (pp. 473-6). IEEE.

[10] Abdmouleh Z, Gastli A, Ben-Brahim L, Haouari M, Al-Emadi NA. Review of optimization techniques applied for the integration of distributed generation from renewable energy sources. Renewable Energy. 2017; 113:266-80.

[11] Surendra K, Vyjayanthi C. Fault level analysis in modern electrical distribution system considering various distributed generations. In international conference on power, energy, control and transmission systems 2018 (pp. 36-42). IEEE.

[12] Hamid ZB, Jipinus S, Musirin I, Othman MM, Salimin RH. Optimal sizing of distributed generation using firefly algorithm and loss sensitivity for voltage stability improvement. Indonesian Journal of Electrical Engineering and Computer Science. 2020;17(2):720-7.

[13] Rueda-Medina AC, Franco JF, Rider MJ, PadilhaFeltrin A, Romero R. A mixed-integer linear programming approach for optimal type, size and allocation of distributed generation in radial distribution systems. Electric Power Systems Research. 2013; 97:133-43.
[14] Wang Z, Chen B, Wang J, Kim J, Begovic MM. Robust optimization based optimal DG placement in microgrids. IEEE Transactions on Smart Grid. 2014; 5(5):2173-82.

[15] Al Abri RS, El-Saadany EF, Atwa YM. Optimal placement and sizing method to improve the voltage stability margin in a distribution system using distributed generation. IEEE Transactions on Power Systems. 2013; 28(1):326-34.

[16] Kaur S, Kumbhar G, Sharma J. A MINLP technique for optimal placement of multiple DG units in distribution systems. International Journal of Electrical Power \& Energy Systems. 2014; 63:609-17.

[17] Ehsan A, Yang Q. Optimal integration and planning of renewable distributed generation in the power distribution networks: a review of analytical techniques. Applied Energy. 2018; 210:44-59.

[18] Kansal S, Kumar V, Tyagi B. Optimal placement of different type of DG sources in distribution networks. International Journal of Electrical Power \& Energy Systems. 2013; 53:752-60.

[19] Abdi S, Afshar K. Application of IPSO-Monte Carlo for optimal distributed generation allocation and sizing. International Journal of Electrical Power \& Energy Systems. 2013; 44(1):786-97.

[20] Zeinalzadeh A, Mohammadi Y, Moradi MH. Optimal multi objective placement and sizing of multiple DGs and shunt capacitor banks simultaneously considering load uncertainty via MOPSO approach. International Journal of Electrical Power \& Energy Systems. 2015; 67:336-49.

[21] Devi S, Geethanjali M. Optimal location and sizing determination of distributed generation and DSTATCOM using particle swarm optimization algorithm. International Journal of Electrical Power \& Energy Systems. 2014; 62:562-70.

[22] Karimyan P, Gharehpetian GB, Abedi M, Gavili A. Long term scheduling for optimal allocation and sizing of DG unit considering load variations and DG type. International Journal of Electrical Power \& Energy Systems. 2014; 54:277-87.

[23] Beltrán JC, Aristizábal AJ, López A, Castaneda M, Zapata S, Ivanova Y. Comparative analysis of deterministic and probabilistic methods for the integration of distributed generation in power systems. Energy Reports. 2020; 6:88-104.

[24] Zhu J. Optimization of power system operation. John Wiley \& Sons; 2015.

[25] Aziz NI, Sulaiman SI, Musirin I, Shaari S. Assessment of evolutionary programming models for singleobjective optimization. In international power engineering and optimization conference 2013 (pp. 304-8). IEEE.

[26] Mirjalili S. The ant lion optimizer. Advances in engineering software. 2015; 83:80-98. 


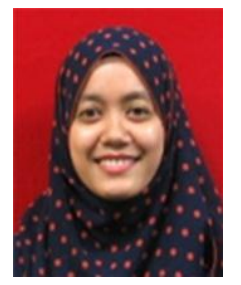

Nur Atiqah Abdul Rahman, received a Bachelor degree in Electrical Engineering in 2011 and Master of Science in Electrical Engineering in 2014 from Universiti Teknologi MARA Malaysia. Currently she is working as a lecturer in Universiti Teknologi MARA Cawangan Sarawak and doing part time $\mathrm{PhD}$ in Electrical Engineering at Universiti Teknologi MARA Malaysia. Her current research interests are Optimization Technique, Distributed Generation and Artificial Intelligence Email: nur_atiqah019@uitm.edu.my

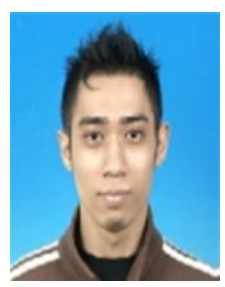

Zulkiffli Abdul Hamid obtained Bachelor in Electrical Engineering (Hons) in 2010 and Phd in Electrical Engineering in 2013 from Universiti Teknologi MARA, Malaysia. His research interest includes sizing FACTS devices, Artificial Intelligence (AI) base optimization technique, power tracing and voltage stability field. Currently, he is a lecturer at Faculty of Electrical Engineering, Universiti Teknologi MARA, Selangor Malaysia and active in publishing articles related to his fields.

Email: zulkiff19947@uitm.edu.my

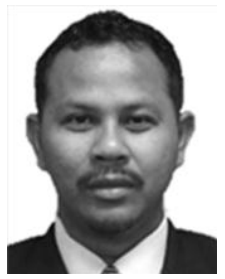

Ismail Musirin received the bachelor's degree (Hons.) in electrical engineering from Universiti Teknologi Malaysia, in 1990, the M.Sc. degree in pulsed power technology from the University of Strathclyde, U.K., in 1992, the Ph.D. degree in electrical engineering from Universiti Teknologi MARA (UiTM), Malaysia, in 2005, and the Diploma degree in electrical power engineering from Universiti Teknologi Malaysia (UTM), in 1987. He started his higher education at UTM. He has been the Head of Programme for the Diploma of Electrical Engineering, UiTM for 3 years from 2004 to 2007, the Head of the Department Electrical Power Engineering in 2007, the Deputy Dean Research and Industrial Networking for 2 years from 2008 to 2010, and the Director for Community of Research UiTM for 4 years from 2014 to 2017 . He is currently a Professor of power system with the Faculty of Electrical Engineering. He has authored and co-authored two books, more than 300 articles in international journal and indexed conferences. His research interests include artificial intelligence, optimization techniques, power system analysis, renewable energy, distributed generation, and power system stability. $\mathrm{He}$ is a Senior Member of the International Association of Computer Science and Information Technology (IACSIT), and a member of the Artificial Immune System Society (ARTIST) and of the International Association of Engineers (IAENG). He is also an International Journal Reviewer of the IEEE Transactions, Science (Elsevier), WSEAS, John Wiley, IET, and some other publishers.

Email: ismailbm@uitm.edu.my

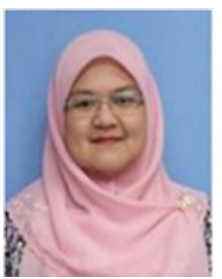

Nur Ashida Salim received her Ph.D in Electrical Engineering from Universiti Teknologi MARA Malaysia in 2015 and MEng (Power System \& Electrical Energy) from Universiti Malaya in 2006. She is currently a lecturer at Universiti Teknologi MARA, MALAYSIA. Her research interests includes Power System Reliability, Power System Planning, Power System Stability and Power System Risk Assessment.

Email: nurashida606@uitm.edu.my

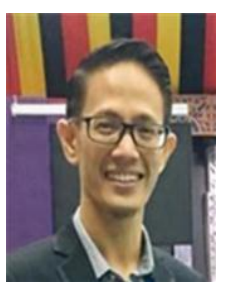

Muhd Firdaus Muhd Yusoff, received a Bachelor degree in Electrical Engineering in 2011 and Master of Engineering in Electrical Engineering in 2015 from Universiti Teknologi Malaysia. He was a design automation engineer from Usains Infotech Sdn. Bhd. and currently he is working as a lecturer in Universiti Teknologi MARA Cawangan Sarawak.

Email: firdaus509@uitm.edu.my 